\title{
Can postpartum maternal urinary iodine be used to estimate iodine nutrition status of newborns?
}

\author{
Pantea Nazeri ${ }^{1}$, Parvin Mirmiran ${ }^{1 *}$, Mehdi Hedayati $^{2}$, Yadollah Mehrabi $^{3}$, Hossein Delshad ${ }^{4}$ and \\ Fereidoun Azizi ${ }^{4}$ \\ ${ }^{1}$ Nutrition and Endocrine Research Center, Research Institute for Endocrine Sciences, Shabid Beheshti University of Medical \\ Sciences, 19395-4763, Tebran, Iran \\ ${ }^{2}$ Cellular and Molecular Research Center, Research Institute for Endocrine Sciences, Shabid Beheshti University of Medical \\ Sciences, 19395-4763, Tebran, Iran \\ ${ }^{3}$ Department of Epidemiology, School of Public Health, Shabid Beheshti University of Medical Sciences, 19835-35511, Tehran, Iran \\ ${ }^{4}$ Endocrine Research Center, Research Institute for Endocrine Sciences, Shabid Beheshti University of Medical Sciences, \\ 19395-4763, Tebran, Iran
}

(Submitted 22 September 2015 - Final revision received 8 December 2015 - Accepted 18 December 2015 - First published online 9 February 2016)

\begin{abstract}
I deficiency can lead to detrimental effects, particularly in neonates and young infants. The aim of this study was to explore whether postpartum maternal urinary I can be used to estimate the I status of newborns. In this cross-sectional study conducted in Tehran, lactating mothers and newborns, within 3-5 d postpartum, were randomly selected. Urine samples were collected from each mother and newborn, and a heel-prick blood sample was obtained from all newborns as part of the routine national newborn screening programme. According to the WHO criteria, median urinary I concentration (UIC) $<100 \mu \mathrm{g} / \mathrm{l}$ and frequency over $3 \%$ of thyroid stimulating hormone (TSH) $>5 \mathrm{mIU} / 1 \mathrm{was}$ considered as I insufficiency. A total of 147 postpartum women and neonates, aged 27.8 (SD 5.3) years and 4.2 (sD 0.6) d, respectively, completed this study. The median UIC was 68.0 (interquartile range (IQR) 39.4-133.5) and 212.5 (IQR 92.3-307.3) $\mu \mathrm{g} / \mathrm{l}$ in postpartum mothers and newborns, respectively. The median neonatal TSH was 1.00 (IQR 0.50-1.70) mIU/l. There was no significant difference in the neonatal UIC and TSH of infants whose mothers had deficient and sufficient urinary I. In the multiple linear regression, neonatal UIC value was associated with maternal urinary I $(P=0.048)$ and parity $(P=0.039)$; a significant association was observed between neonatal TSH and infant sex $(P=0.038)$ and birth weight $(P=0.049)$. The findings of our study demonstrate that, despite postpartum mothers being mildly I deficient, I status of their infants was adequate as assessed by UIC and TSH values. It seems factors other than maternal urinary I may influence the I status in newborns.
\end{abstract}

Key words: Postpartum mothers: Newborns: Urinary iodine: Thyroid stimulating hormone

I deficiency is among the four leading micronutrient deficiencies in the world, which can produce detrimental effects, particularly in neonates and young infants. Consequences of I deficiency during these critical periods are mainly developmental delays, irreversible brain damage and mental retardation ${ }^{(1,2)}$. Despite global progress in elimination of I deficiency, today over thirtyfive million newborns remain unprotected from the lifelong consequences of brain damage associated with I deficiency ${ }^{(3)}$.

In order to evaluate the efficiency of national programmes implemented for elimination of I deficiency and to monitor I status of populations, median urinary I concentration (UIC), thyroid size, neonatal thyroid stimulating hormone (TSH) and thyroglobulin concentrations can all serve as indicators ${ }^{(4)}$. On a population basis, there is a negative association between maternal UIC and neonatal TSH values, specifically in countries with moderate-to-severe I deficiency ${ }^{(5)}$; however, in countries with mild-to-borderline I deficiency, decline in UIC has not been accompanied by change in blood spot TSH concentration, indicating that neonatal TSH may not have the sensitivity needed to detect mild I deficiency ${ }^{(5)}$. Moreover, there is evidence indicating an inconsistent relationship between maternal I status and neonatal UIC levels. In I-deficient countries such as Ireland ${ }^{(6)}$, Portugal ${ }^{(7)}$, Turkey ${ }^{(8)}$ and Niger ${ }^{(9)}$, median neonatal UIC was inadequate along with I deficiency among postpartum women. However, findings of a few studies conducted in I-sufficient areas are inconclusive: in some, I adequacy among neonates was also accompanied by I sufficiency among lactating mothers ${ }^{(10,11)}$; others, however, report

Abbreviations: IQR, interquartile range; TSH, thyroid stimulating hormone; UIC, urinary iodine concentration.

* Corresponding author: P. Mirmiran, fax +98 212203 60657, email mirmiran@endocrine.ac.ir 
decreased-to-suboptimal I status among postpartum women, despite I adequacy among their neonates ${ }^{(12)}$.

The Islamic Republic of Iran was once known as an area of I deficiency. Production and nationwide consumption of iodised salt containing 20-40 parts per million I began in 1990 and became mandatory for household consumption by 1994. In 2000, Iran was declared I deficiency disorders (IDD) free, and national surveys conducted every 5-7 years have shown sustainable elimination of IDD in schoolchildren ${ }^{(13)}$. However, I sufficiency in the general population as assessed by the median UIC among school-aged children was not accompanied by the adequate median UIC among pregnant and lactating women and their infants. Previous studies conducted in Iran, comparing urinary I values of postpartum mothers and their infants, have demonstrated that median UIC in postpartum mothers ranged from low to borderline levels, whereas urinary I of their neonates was within optimal range and no definitive correlations between maternal and neonatal UIC were reported ${ }^{(12,14)}$.

Therefore, considering the limited data and controversial results available regarding the correlation between maternal urinary I levels during postpartum periods and I nutrition status of their infants in countries with different I status, the present study was designed to explore whether urinary I of the postpartum mothers residing in an area with I sufficiency can be used to estimate I status of newborns using UIC and TSH values.

\section{Methods}

\section{Subjects}

For this cross-sectional study conducted from April to December 2014 in Tehran, the capital city of Iran, four healthcare centres responsible for screening newborns with congenital hypothyroidism were randomly selected; in each centre, on the first visit, within 3-5 d postpartum, mother-newborn pairs were included to the study based on the following inclusion criteria: healthy mothers with no history of thyroid disorders and currently not using I-containing supplements and disinfectants; mothers having a singleton birth and who were exclusively breastfeeding; and neonates born full-term (gestational age, 37-42 weeks), aged 3-5 d and with normal birth weight (2500-4200 g). Using an interviewer-administered questionnaire, maternal information on age, education, occupation, last pregnancy, gravidity, parity, history of abortion in previous pregnancies, use of I-containing supplements during last pregnancy and the type of delivery were documented, and newborn demographic information including birth date, sex and birth weight, height and head measurements was obtained. Written informed consent was obtained after the study protocol and objectives had been fully explained to all postpartum mothers and/or their husbands. The present study was approved by the Ethics Committee of the Research Institute for Endocrine Sciences, Shahid Beheshti University of Medical Sciences. Of a total of 262 mother-newborn pairs initially enrolled, newborns without urine samples ( $n$ 16) as well as mothers ( $n$ 22) and newborns ( $n$ 77) with urinary I levels $>800 \mu \mathrm{g} / \mathrm{l}$ (considered outliers, defined as more than 3 SD from the mean) were excluded; hence, 147 mother-newborn pairs remained for the current analysis.

\section{Thyroid stimulating hormone concentration}

Heel-prick blood samples were obtained by trained nurses from all newborns within 3-5 d after birth, as part of routine newborn screening, spotted on filter paper ((Schleicher \& Schuell NO 903) S\&S 903) and air-dried for $2-3 \mathrm{~h}$. The samples were sent to the reference screening laboratory by express mail service for TSH values to be assayed within 7-10 d. Neonates with abnormal TSH levels on screening, that is, TSH level $\geq 5 \mathrm{mIU} / 1$ in the heel prick test, were recalled for confirmatory tests on the basis of the serum TSH and thyroxine concentrations.

\section{Urine collection}

At the first visit, labelled plastic bottles and adhesive paediatric urine bags (SUPA medical services) were provided to collect spot urine samples of each postpartum mother and her newborn according to the detailed instructions provided. Mothers were asked to collect a casual urine sample at random at any time during the day; they were also instructed to clean the genital region of their newborns and to place the entire penis in the bag and attach the adhesive to the skin for boys and to fit the bag over the labia for girls. If urine samples of newborns could not be collected using adhesive urine bags after three attempts, mothers were asked collect samples by holding a specimen bottle in the urine stream. All samples were collected and sent to the iodine laboratory of the Research Institute for Endocrine Sciences, where they were transferred into screw-top labelled plastic vials. The aliquots were kept frozen at $-20^{\circ} \mathrm{C}$ until I concentrations were measured.

\section{Laboratory measurements}

I concentration in urine samples was analysed using the Sandell-Kolthoff (acid digestion) reaction ${ }^{(15)}$, and the results are expressed as micrograms of I per litre of urine. Intra-assay $\mathrm{CV}$ at UIC values of $8.5,17.5$ and $36.0 \mu \mathrm{g} / \mathrm{l}$ were $8.5,6.2$ and $8.0 \%$, respectively. The inter-assay $\mathrm{CV}$ at concentrations of $8 \cdot 5,17 \cdot 4$ and $36.4 \mu \mathrm{g} / 1$ were $10 \cdot 3,9 \cdot 7$ and $8.0 \%$, respectively; TSH concentration was determined by ELISA using available neonatal TSH kits (Kimia Pajouhan Co.). The minimal detectable concentration of TSH in this assay is estimated to be $1 \cdot 2 \mu \mathrm{IU} / \mathrm{ml}$. Intra-assay $\mathrm{CV}$ at $\mathrm{TSH}$ concentrations of 5.1, 8.6, 17.9 and $30 \mathrm{mIU} / 1$ were $11 \cdot 6,8 \cdot 0,7.4$ and $6 \cdot 6 \%$, respectively. The interassay CV for different methods at TSH concentrations of $4 \cdot 7,8 \cdot 8$, 18.6 and $31.7 \mathrm{mIU} / 1$ were $13 \cdot 2,9 \cdot 8,7 \cdot 2$ and $7 \cdot 3 \%$, respectively.

\section{Definition of terms}

In postpartum women and newborns, according to WHO/International Council for the Control of Iodine Deficiency Disorders (ICCIDD)/UNICEF criteria, median UIC values $<100$ and $\geq 100 \mu \mathrm{g} / 1$ were representative of deficient and sufficient urinary I, respectively ${ }^{(4)}$. The TSH cut-off point was set at $5 \mathrm{mIU} / \mathrm{l}$, and a frequency $<3 \%$ for TSH $>5$ mIU/1 was considered population I sufficiency ${ }^{(16)}$.

\section{Statistics analysis}

Frequency distribution (percentage), mean values and standard deviations and medians and interquartile ranges were 
expressed for categorical and continuous variables. Normality of the variables was assessed by the Kolmogorov-Smirnov test and histogram chart. $\chi^{2}$ and Mann-Whitney $U$ test or $t$ tests were used to assess significance of differences for categorical and continuous variables in postpartum mothers and newborns and also among mothers with median UIC $<100$ and $\geq 100 \mu \mathrm{g} / \mathrm{l}$. The skewed variables were log-transformed before analysis. To identify factor(s) affecting neonatal UIC and TSH values, multiple linear regression was used. Factors considered in this analysis were as follows: maternal UIC, mothers' occupation and educational grade, gravidity, parity, delivery type, infant sex and birth weight. Statistical analyses were carried out using IBM SPSS for windows (version 20.0, 2011; IBM Corp.), $P$ values $<0.05$ were considered to be significant.

\section{Results}

A total of 147 postpartum women and newborns, aged $27 \cdot 8$ (SD 5.3) years and $4.2(\mathrm{sD} 0.6) \mathrm{d}$, respectively, participated in this study. Table 1 shows the basic characteristics of the postpartum women and their neonates. The mean grade of education of the women was 11.1 ( $\mathrm{sD} 3.4$ ) years; over $90.0 \%$ of the mothers were housewives; over half of the postpartum mothers had multigravidity (62.6\%) and multiparity (55.1\%); only about $5.0 \%$ of the mothers had used I-containing supplements during pregnancy; and approximately $60.0 \%$ of them had had caesarean sections. In all, $54 \%$ of newborns were male and $46 \cdot 3 \%$ were female; mean values for birth weight, height and head circumference among newborns were 3345 (SD 421)g, $50 \cdot 3(\mathrm{sD} 2 \cdot 0) \mathrm{cm}$ and $35 \cdot 0(\mathrm{sD} 1.4) \mathrm{cm}$, respectively.

Data on neonatal UIC and TSH levels according to maternal urinary I are shown in Table 2. The median UIC was 68.0 (interquartile range (IQR) 39.4-133.5) $\mu \mathrm{g} / \mathrm{l}$ in postpartum mothers and was 212.5 (IQR 92.3-307.3) $\mu \mathrm{g} / 1$ in newborns, respectively. The median UIC values in mothers with deficient and sufficient urinary I were 46.6 (IQR 35.2-70.8) and 173.6 (IQR 144.5-211.4) $\mu \mathrm{g} / \mathrm{l}$, respectively; values of UIC of neonates born to mothers with deficient and sufficient urinary I were 192.8 (IQR 85.0-284.3) and 243.0 (IQR 109.3-331.2) $\mu \mathrm{g} / \mathrm{l}$, respectively $(P=0 \cdot 100)$. Urinary I of mothers and neonates did not differ between those who had natural vaginal delivery (NVD) and those who had a caesarean section.

The median neonatal TSH value was 1.00 (IQR 0.501.70) $\mathrm{mIU} / \mathrm{l}$; median TSH values were 1.05 (IQR $0 \cdot 42-1.80) \mathrm{mIU} / \mathrm{l}$ for neonates born to mothers with deficient UIC and 1.00 (IQR $0.75-1.55) \mathrm{mIU} / 1$ for neonates born to mothers with sufficient UIC $(P=0 \cdot 930)$. Frequency distributions of TSH values are presented in Table 2. Of neonates, $1.4,5.5$ and $16.6 \%$ had TSH levels $>5,>3$ and $>2 \mathrm{mIU} / \mathrm{l}$, respectively. There was no difference in neonatal TSH in mothers who had NVD, as compared with those who had a caesarean section $(1.1 \quad v .0 .9 \mathrm{mIU} / \mathrm{l}$, $P=0 \cdot 158)$.

Factors associated with neonatal UIC and TSH values are presented in Table 3. Maternal UIC was not associated with neonatal UIC $(\beta=0.156, P=0.094)$ and TSH values $(\beta=0.129$, $P=0.236)$ using univariate analysis; however, in the multiple linear regression, neonatal UIC value was significantly associated with maternal urinary I $(\beta=0 \cdot 191, P=0 \cdot 048)$ and parity
Table 1. Baseline characteristics of mothers and newborns 3-5 d postpartum

(Numbers and percentages; mean values and standard deviations)

\begin{tabular}{|c|c|c|c|}
\hline Characteristics & $n$ & & $\%$ \\
\hline \multicolumn{4}{|l|}{ Mothers } \\
\hline \multicolumn{4}{|l|}{ Age (years) } \\
\hline Mean & \multicolumn{3}{|c|}{27.8} \\
\hline SD & \multicolumn{3}{|c|}{5.3} \\
\hline \multicolumn{4}{|c|}{ Education (years) } \\
\hline Mean & \multicolumn{3}{|c|}{11.1} \\
\hline SD & \multicolumn{3}{|c|}{3.4} \\
\hline \multicolumn{4}{|l|}{ Occupation } \\
\hline Employee & 11 & & $7 \cdot 5$ \\
\hline Housewives & 136 & & 92.5 \\
\hline \multicolumn{4}{|l|}{ Gravidity } \\
\hline Primigravidity & 55 & & $37 \cdot 4$ \\
\hline Multigravidity & 92 & & $62 \cdot 6$ \\
\hline \multicolumn{4}{|l|}{ Parity } \\
\hline Primiparity & 65 & & $44 \cdot 9$ \\
\hline Multiparity & 81 & & $55 \cdot 1$ \\
\hline \multicolumn{4}{|c|}{ History of abortion } \\
\hline Yes & 27 & & $18 \cdot 4$ \\
\hline No & 120 & & 81.6 \\
\hline \multicolumn{4}{|c|}{$\begin{array}{l}\text { Use of I-containing supplements during } \\
\text { pregnancy }\end{array}$} \\
\hline Yes & 7 & & 4.9 \\
\hline No & 74 & & $51 \cdot 7$ \\
\hline Don’t know & 62 & & $43 \cdot 4$ \\
\hline \multicolumn{4}{|l|}{ Delivery type } \\
\hline NVD & 59 & & $40 \cdot 1$ \\
\hline CS & 88 & & $59 \cdot 9$ \\
\hline \multicolumn{4}{|l|}{ Newborns } \\
\hline \multicolumn{4}{|l|}{ Sex } \\
\hline Male & 79 & & $53 \cdot 7$ \\
\hline Female & 68 & & $46 \cdot 3$ \\
\hline \multicolumn{4}{|l|}{ Birth weight (g) } \\
\hline Mean & \multicolumn{3}{|c|}{3345} \\
\hline SD & \multicolumn{3}{|c|}{421} \\
\hline \multicolumn{4}{|l|}{ Birth height (cm) } \\
\hline Mean & \multicolumn{3}{|c|}{50.3} \\
\hline SD & \multicolumn{3}{|c|}{2.0} \\
\hline \multicolumn{4}{|c|}{ Birth head circumference $(\mathrm{cm})$} \\
\hline Mean & \multicolumn{3}{|c|}{35.0} \\
\hline SD & \multicolumn{3}{|c|}{1.4} \\
\hline
\end{tabular}

NVD, natural vaginal delivery; CS, caesarean section.

( $\beta=0.408, P=0.039)$. In addition, a significant association was found between TSH concentration and infant sex $(\beta=-0 \cdot 348$, $P=0.038)$ and birth weight $(\beta=0.391, P=0.049)$. Neither neonatal UIC nor TSH values were associated with mothers' occupation and education, gravidity and type of delivery.

\section{Discussion}

Findings of the current study indicate that Tehranian postpartum mothers, but not their newborns, had marginally suboptimal I status, as defined by the median UIC established by the World Health Organization $^{(4)}$; however, on the basis of newborn TSH concentration as an index of population I status (a frequency $<3 \%$ for TSH $>5 \mathrm{mIU} / 1$ considered as I sufficiency), mothers and newborns were both classified as I sufficient. In addition, a decline in maternal urinary I was not accompanied by alteration in neonatal UIC and TSH levels.

On the basis of the frequency of neonatal TSH values $>5 \mathrm{mIU} / 1$ in determining population I status, monitoring 
Table 2. Urinary iodine and neonatal thyrotropin concentrations of 3-5 d old newborns according to maternal urinary iodine concentration (UIC) (Numbers and percentages; median and interquartile range (IQR))

\begin{tabular}{|c|c|c|c|c|c|c|}
\hline \multirow[b]{3}{*}{ Variables } & \multicolumn{6}{|c|}{ Maternal UIC $(\mu \mathrm{g} / \mathrm{l})$} \\
\hline & \multicolumn{2}{|c|}{ Total } & \multicolumn{2}{|c|}{$\mathrm{UIC}<100$} & \multicolumn{2}{|c|}{$\mathrm{UIC} \geq 100$} \\
\hline & $n$ & $\%$ & $n$ & $\%$ & $n$ & $\%$ \\
\hline & 147 & 100 & 102 & $69 \cdot 4$ & 45 & 30.6 \\
\hline \multicolumn{7}{|c|}{ Neonatal UIC $(\mu \mathrm{g} / \mathrm{l})$} \\
\hline Median & \multirow{2}{*}{\multicolumn{2}{|c|}{$\begin{array}{c}212 \cdot 5 \\
92 \cdot 3-307 \cdot 3\end{array}$}} & \multirow{2}{*}{\multicolumn{2}{|c|}{$\begin{array}{c}192 \cdot 8^{\star} \\
85 \cdot 0-284 \cdot 3\end{array}$}} & \multirow{2}{*}{\multicolumn{2}{|c|}{$\begin{array}{c}243 \cdot 0 \\
109 \cdot 3-331 \cdot 2\end{array}$}} \\
\hline IQR & & & & & & \\
\hline \multicolumn{7}{|c|}{ Neonatal TSH (mlU/l) } \\
\hline Median & \multirow{2}{*}{\multicolumn{2}{|c|}{$\begin{array}{c}1.00 \\
0.50-1.70\end{array}$}} & \multirow{2}{*}{\multicolumn{2}{|c|}{$\begin{array}{c}1.05^{\star} \\
0.42-1.80\end{array}$}} & \multirow{2}{*}{\multicolumn{2}{|c|}{$\begin{array}{c}1.00 \\
0.75-1.55\end{array}$}} \\
\hline IQR & & & & & & \\
\hline $\mathrm{TSH}>5$ & 2 & 1.4 & 2 & $2 \cdot 0$ & 0 & 0.0 \\
\hline $\mathrm{TSH}>3$ & 8 & 5.5 & 6 & 6.0 & 2 & 4.4 \\
\hline $\mathrm{TSH}>2$ & 24 & $16 \cdot 6$ & 18 & $18 \cdot 0$ & 6 & $13 \cdot 3$ \\
\hline
\end{tabular}

TSH, thyroid stimulating hormone.

* No significant difference between the two maternal UIC groups.

Table 3. Factors associated with neonatal urinary iodine and thyroid stimulating hormone (TSH) concentrations by multiple linear regression ${ }^{\star}$ ( $\beta$ Coefficients and $95 \%$ confidence intervals)

\begin{tabular}{|c|c|c|c|c|}
\hline \multirow[b]{2}{*}{ Factors } & \multicolumn{2}{|c|}{ Neonatal UIC } & \multicolumn{2}{|c|}{ Neonatal TSH } \\
\hline & $\beta$ & $95 \% \mathrm{Cl}$ & $\beta$ & $95 \% \mathrm{Cl}$ \\
\hline Maternal UIC** & 0.191 & $0.002,0.380$ & 0.133 & $-0.086,0.352$ \\
\hline Education & 0.039 & $-0.007,0.085$ & 0.020 & $-0.033,0.074$ \\
\hline Mothers' occupation & -0.309 & $-0.877,0.259$ & 0.353 & $-0.305,1.012$ \\
\hline Type of delivery & -0.021 & $-0.315,0.273$ & -0.342 & $-0.687,0.002$ \\
\hline Gravidity & -0.220 & $-0.531,0.091$ & -0.152 & $-0.517,0.212$ \\
\hline Parity & 0.408 & $0.021,0.796$ & 0.256 & $-0.202,0.715$ \\
\hline Sex of neonate & -0.206 & $-0.487,0.076$ & -0.348 & $-0.677,-0.019$ \\
\hline Birth weight & 0.080 & $-0.254,0.415$ & 0.391 & $0.002,0.780$ \\
\hline$R^{2}$ adjusted & \multicolumn{2}{|c|}{0.041} & \multicolumn{2}{|c|}{0.049} \\
\hline
\end{tabular}

UIC, urinary I concentration.

* Neonatal UIC and TSH and maternal UIC values log-transformed.

intervention programmes have been successful in some countries such as Poland, Thailand, Belgium, Ireland and Switzerland $^{(5)}$; however, on the basis of the latest recommendations of the WHO/UNICEF/ICCIDD, newborn TSH level per se is not included among the indicators of I nutrition status $^{(4)}$, which is because many confounding issues (such as maternal I status, prematurity, type of delivery, exposure to I-containing antiseptics, time of sampling and TSH assay methodology) may alter newborn TSH, making this variable a less sensitive and reliable monitoring tool for determining I deficiency $^{(5)}$. It has been suggested that median UIC in conjunction with neonatal TSH can provide a more reliable assessment of population I status ${ }^{(5,17)}$. As shown in Belgium and the UK, considered both as mildly I-deficient areas, neonatal TSH may lack the sensitivity required to detect mild I deficiency ${ }^{(18,19)}$. Our study also demonstrated inconsistent I statuses of postpartum mothers and newborns assessed by median UIC and neonatal TSH values, due to the aforementioned reasons. Although, data assessing blood spot TSH from neonates revealed no evidence to support the notion that the population studied is I deficient (only $1.4 \%$ of neonates had TSH $>5 \mathrm{mIU} / \mathrm{l}$ ), I status (expressed as the median UIC) of Tehranian postpartum mothers, but not newborns, was below at $100 \mu \mathrm{g} / \mathrm{l}$.
Data on newborn screening revealed a negative correlation between neonatal TSH concentration and UIC in their mothers. In Zaire and India, neonatal TSH concentration was significantly elevated in the cord blood of offspring of mothers suffering from moderate-to-severe I deficiency ${ }^{(20)}$. A study comparing maternal and neonatal thyroid status in Nigeria demonstrated that mean plasma TSH was significantly higher in neonates whose mothers had significantly lower UIC levels and higher goitre rates ${ }^{(21)}$. In countries with moderate I deficiency (e.g. Turkey, Thailand and Hong Kong), the frequency of serum $\mathrm{TSH}>5 \mathrm{mIU} / 1$ was inversely related to maternal $\mathrm{UIC}^{(8,22,23)}$. However, studies from countries with mild I deficiency such as Australia and Denmark, where the frequency of $\mathrm{TSH}>5 \mathrm{mIU} / 1$ is often $<3 \%$, did not find the expected negative correlation between neonatal whole blood $\mathrm{TSH}$ and maternal UIC ${ }^{(24,25)}$. Our finding of neonatal $\mathrm{TSH}$ values within normal range, despite mild maternal I deficiency, is in agreement with several studies, which have demonstrated that a decline in maternal urinary I is not always accompanied by alteration in I status as assessed by neonatal TSH levels ${ }^{(5)}$. However, consistent with our results, most studies have reported that male infants generally have higher TSH levels and their birth weight is also positively associated with TSH levels ${ }^{(26)}$. 
The main challenge in using median UIC in newborns is the difficulty of sample collection; hence, the best criteria for assessing the newborns' degree of I deficiency have not yet been established due to lack of sufficient data for urinary I in this age group. The WHO recommends that a median UIC $>$ $100 \mu \mathrm{g} / \mathrm{l}$ is adequate for assessing the I status of children aged $<2$ years ${ }^{(4)}$; however, the study by Zimmermann ${ }^{(27)}$ demonstrated that the current WHO median UIC cut-off for I sufficiency in infancy may be too high for the 1st week after birth. Dorey \& Zimmermann ${ }^{(28)}$ reported the following median UIC in children $<2$ years from I-sufficient countries: Canada ( $n$ 81), $148 \mu \mathrm{g} / \mathrm{l}$; the Netherlands ( $n$ 64, $n$ 36), 162 and $150 \mu \mathrm{g} / \mathrm{l}$, respectively; Sweden ( $n$ 39, $n$ 61) 112 and $96 \mu \mathrm{g} / \mathrm{l}$, respectively; and Czech Republic ( $n$ 181), 92-109 $\mu \mathrm{g} / \mathrm{l}$. Moreover, there are limited studies that simultaneously include both neonatal TSH and median UIC in screening programmes for newborns. In Switzerland, despite a national survey of healthy, term, euthyroid breast-fed infants, aged $0-5 \mathrm{~d}$ ( $n$ 634), indicating a median UIC of $77 \mu \mathrm{g} / \mathrm{l}$, the frequency of $\mathrm{TSH}>5 \mathrm{mIU} / \mathrm{l}$ in the newborn screening programme between 1999 and 2004 was $1.7 \%^{(29)}$; however, in the present study, the median UIC of newborns was higher $(n 147,212.5 \mu \mathrm{g} / \mathrm{l})$ than that reported from the I-sufficient areas, and the TSH concentrations of the newborns met the WHO criteria recommendations.

As the requirement of $\mathrm{I}$ increases substantially during pregnancy and lactation, it is conceivable that - if reserves and dietary I intake are low at baseline - subsequent gestations and lactations may deplete the maternal I reserves further, and hence produce relationship with increased parity. Although there are no studies specifically demonstrating an association between parity and I status, our study showed that median urinary I in mothers who had three or more children was lower compared with mothers with only one child (61.3 $\mu \mathrm{g} / \mathrm{l}, n 26 v$. $81.2 \mu \mathrm{g} / 1, n 65)$ (data not shown). On the other hand, maternal I sufficiency is particularly important for exclusively breast-fed infants, in whom breast milk is the sole source of I nutrition during a critical period of growth and development. Therefore, on a biological basis, it might be expected that a positive association between urinary I status in mothers and exclusively breast-fed infants be found; however, our findings indicate that despite maternal I deficiency I status of their infants was adequate. There is some evidence of transfer of I from mothers to newborns as shown in the current study, in which higher UIC of neonates was associated with maternal urinary I - a finding compatible with our previous study conducted in Tehran ${ }^{(12)}$ and other investigations from Turkey ${ }^{(8)}$ and Ireland ${ }^{(6)}$. These studies have indicated that maternal UIC in breast-feeding mothers was significantly lower than their infants as follows: in Tehran (107v. $271 \mu \mathrm{g} / \mathrm{l})$, Turkey (40 $v .85 \mu \mathrm{g} / \mathrm{l})$ and Ireland 76.5 $v .100 \mu \mathrm{g} / 1)$; a similar pattern was observed in the recent study from Turkey ( $84 v .279 \mu \mathrm{g} / \mathrm{l})$; however, I deficiency in nursing mothers and I excess in their newborns was attributed to the use of antiseptics containing $\mathrm{I}^{(30)}$.

The main strengths of this study are the estimation of newborn I nutrition status based on postpartum maternal UIC, for the first time in an area of I sufficiency, and assessment of I status among newborns simultaneously by two variables (UIC and TSH) in the early neonatal period. However, among limitations, using a single random urine sample may be a poor indicator to determine an individual's I status, because of significant day-to-day variation in salt intake, which is the main source of dietary I in many countries, and also variations in hydration in individuals. Previous studies on $\mathrm{Na}$ intake have indicated that at least five 24-h urine collections are required to obtain a representative estimate of individual $\mathrm{Na}$ excretion. Therefore, approximately ten repeat spot urine samples or 24-h collections are needed to estimate individual I intakes at a precision of $20 \%{ }^{(31)}$. Moreover, as discussed above, caution should be taken in interpreting these results due to categorisation of maternal I status on the basis of a single spot urinary I excretion, which raises the potential risk of misclassification. Another potential limitation of this study is related to the cross-sectional design of this study that cannot establish causality relationships.

In conclusion, although on a biological basis, it could be expected that a positive association between urinary I status in mothers and exclusively breast-fed infants be found; however, our findings indicate that despite Tehranian postpartum mothers being mildly I deficient the I status of their infants was adequate as defined by the median UIC values. Furthermore, a decline in maternal urinary I was not accompanied by alteration in I status of neonates, as assessed by TSH levels. It seems that factors other than maternal urinary I may influence UIC and TSH values, both indicators of I status in newborns.

\section{Acknowledgements}

This study was supported by a financial grant from the Research Institute of Endocrine Sciences, Shahid Beheshti University of Medical Sciences. The authors express their appreciation and gratitude to Niloofar Shiva for critical editing of English grammar and syntax of the manuscript.

This research received no specific grant from any funding agency, commercial or not-for-profit sectors.

P. N. contributed to the design, data analysis; P. M. and F. A. contributed to the reading and final approval of the manuscript; P. M., F. A. and M. H. contributed to the design of the study; Y. M. contributed to the statistical analysis; P. N., P. M., M. H., F. A. and Y. M. contributed to the writing of the manuscript.

None of the authors has any personal or financial conflicts of interest to declare.

\section{References}

1. Bath SC, Steer CD, Golding J, et al. (2013) Effect of inadequate iodine status in UK pregnant women on cognitive outcomes in their children: results from the Avon Longitudinal Study of Parents and Children (ALSPAC). Lancet 382, 331-337.

2. Zimmermann MB, Jooste PL \& Pandav CS (2008) Iodine-deficiency disorders. Lancet 372, 1251-1262.

3. United Nations International Children's Emergency Fund (2008) UNICEF data: monitoring the situation of children and women. http://unistage.jjcbigideas.com/nutrition/iodine (accessed December 2014).

4. World Health Organization (2007) Assessment of iodine deficiency disorders and monitoring their elimination: a guide for programme managers. whqlibdoc.who.int/publications/ 2007/9789241595827_eng.pdf, (accessed December 2014). 
5. Li M \& Eastman CJ (2010) Neonatal TSH screening: is it a sensitive and reliable tool for monitoring iodine status in populations? Best Pract Res Clin Endocrinol Metab 24, 63-75.

6. Smyth PP, Hetherton AM, Smith DF, et al. (1997) Maternal iodine status and thyroid volume during pregnancy: correlation with neonatal iodine intake. J Clin Endocrinol Metab 82, 2840-2843.

7. Costeira MJ, Oliveira P, Ares S, et al. (2009) Iodine status of pregnant women and their progeny in the Minho Region of Portugal. Thyroid 19, 157-163.

8. Simsek E, Karabay M \& Kocabay K (2005) Neonatal screening for congenital hypothyroidism in West Black Sea area, Turkey. Int J Clin Pract 59, 336-341.

9. Sadou H, Moussa Y, Alma MM, et al. (2013) Iodine status of breastfed infants and their mothers after sixteen years of Universal Dietary Salt Iodization program in Dosso, Niger. Open Nutr J 7, 7-12.

10. Hashemipour M, Nasri P, Hovsepian S, et al. (2010) Urine and milk iodine concentrations in healthy and congenitally hypothyroid neonates and their mothers. Endokrynol Pol 61, 371-376.

11. Wang Y, Zhang Z, Ge P, et al. (2009) Iodine status and thyroid function of pregnant, lactating women and infants $(0-1 \mathrm{yr})$ residing in areas with an effective Universal Salt Iodization program. Asia Pac J Clin Nutr 18, 34-40.

12. Ordookhani A, Pearce EN, Hedayati M, et al. (2007) Assessment of thyroid function and urinary and breast milk iodine concentrations in healthy newborns and their mothers in Tehran. Clin Endocrinol (Oxf) 67, 175-179.

13. Delshad H, Amouzegar A, Mirmiran P, et al. (2012) Eighteen years of continuously sustained elimination of iodine deficiency in the Islamic Republic of Iran: the vitality of periodic monitoring. Thyroid 22, 415-421.

14. Bazrafshan HR, Mohammadian S, Ordookhani A, et al. (2005) An assessment of urinary and breast milk iodine concentrations in lactating mothers from Gorgan, Iran, 2003. Thyroid 15, 1165-1168.

15. Hedayati M, Khazan M, Yaghmaee P, et al. (2011) Rapid microwave digestion and microplate reading format method for urinary iodine determination. Clin Chem Lab Med 49 , 281-284.

16. Delange F (1994) The disorders induced by iodine deficiency. Thyroid 4, 107-128.

17. Burns R, Mayne PD, O'Herlihy C, et al. (2008) Can neonatal TSH screening reflect trends in population iodine intake? Thyroid 18, 883-888.

18. Vandevijvere S, Coucke W, Vanderpas J, et al. (2012) Neonatal thyroid-stimulating hormone concentrations in Belgium: a useful indicator for detecting mild iodine deficiency? PLOS ONE 7, e47770.

19. Evans C, Barry Nix A, Hillier S, et al. (2014) Neonatal blood TSH concentration in Wales (UK): an indicator of iodine sufficiency. Clin Endocrinol (Oxf) 81, 606-609.

20. Delange F (1998) Screening for congenital hypothyroidism used as an indicator of the degree of iodine deficiency and of its control. Thyroid 8, 1185-1192.

21. Ojule AC \& Osotimehin BO (1998) Maternal and neonatal thyroid status in Saki, Nigeria. Afr J Med Med Sci 27, 57-61.

22. Jaruratanasirikul S, Sangsupawanich P, Koranantakul O, et al. (2009) Maternal iodine status and neonatal thyroid-stimulating hormone concentration: a community survey in Songkhla, southern Thailand. Public Health Nutr 12, 2279-2284.

23. Kung AW, Lao TT, Low LC, et al. (1997) Iodine insufficiency and neonatal hyperthyrotropinaemia in Hong Kong. Clin Endocrinol (Oxf) 46, 315-319.

24. McElduff A, McElduff P, Gunton JE, et al. (2002) Neonatal thyroid-stimulating hormone concentrations in northern Sydney: further indications of mild iodine deficiency? Med J Aust 176, 317-320.

25. Nohr SB \& Laurberg P (2000) Opposite variations in maternal and neonatal thyroid function induced by iodine supplementation during pregnancy. J Clin Endocrinol Metab 85, 623-627.

26. Herbstman J, Apelberg BJ, Witter FR, et al. (2008) Maternal, infant, and delivery factors associated with neonatal thyroid hormone status. Thyroid 18, 67-76.

27. Zimmermann MB (2009) Iodine deficiency in pregnancy and the effects of maternal iodine supplementation on the offspring: a review. Am J Clin Nutr 89, 668S-672S.

28. Dorey CM \& Zimmermann MB (2008) Reference values for spot urinary iodine concentrations in iodine-sufficient newborns using a new pad collection method. Thyroid 18, 347-352.

29. Zimmermann MB, Aeberli I, Torresani T, et al. (2005) Increasing the iodine concentration in the Swiss iodized salt program markedly improved iodine status in pregnant women and children: a 5-y prospective national study. Am J Clin Nutr 82, 388-392.

30. Yaman AK, Demirel F, Ermis B, et al. (2013) Maternal and neonatal urinary iodine status and its effect on neonatal TSH levels in a mildly iodine-deficient area. J Clin Res Pediatr Endocrinol 5, 90-94.

31. König F, Andersson M, Hotz K, et al. (2011) Ten repeat collections for urinary iodine from spot samples or 24-hour samples are needed to reliably estimate individual iodine status in women. J Nutr 141, 2049-2054. 